\title{
A IMPORTÂNCIA DA PESQUISA-AÇÃO NO CONTEXTO DE EMPREENDIMENTOS MINERÁRIOS
}

ISABELLA DOMETILA MARTINS DE ASSIS*

DIAS, André Luiz Freitas; OLIVEIRA, Lucas Furiati de (Org.). Violências de Mercado e de Estado no Contexto do Empreendimento Minerário Minas-Rio, Conceição do Mato Dentro - MG, 2015 a 2017. São Carlos: Scienza, 2018. 242 p. E-book.

Resumo Nesta resenha sobre o livro Violências de Mercado e de Estado no Contexto do Empreendimento Minerário Minas-Rio, Conceição do Mato Dentro - MG, 2015 a 2017, analisou-se a importância e a relevância da adoção do método científico de pesquisa-ação para a produção de conhecimento científico no âmbito das ciências sociais aplicadas, especificamente no campo de atuação do Direito.

PALAVRAS-Chave mineração; conflitos; pesquisa-ação.

\section{THE IMPORTANCE OF ACTION RESEARCH IN THE CONTEXT OF MINING ENTERPRISES}

Critical review of the digital book Market and State Violence in the Context of the Minas-Rio Mining Enterprise, Conceição do Mato Dentro - MG, 2015 to 2017 by DIAS, André Luiz Freitas; OLIVEIRA, Lucas Furiati de (Org.). São Carlos: Scienza, 2018. $242 \mathrm{p}$.

ABSTRACT In this review on the book "Market and State Violence in the Context of the Minas-Rio Mining Enterprise, Conceição do Mato Dentro - MG, 2015 to 2017", the importance and relevance of adopting the scientific method of action research for the production of scientific knowledge in the field of applied social sciences, specifically in the field of law.

KEYWORDS mining; conflicts; action research.

* Universidade Federal de Minas Gerais (UFMG). 
Os autores coordenadores do livro ora resenhado são André Luiz Freitas Dias e Lucas Furiati de Oliveira.

O autor, André Luiz Freitas Dias, é professor e pesquisador-extensionista do Departamento de Psicologia da Universidade Federal de Minas Gerais (UFMG), credenciado na instituição como membro permanente do Programa de Pós-Graduação em Direito (Mestrado e Doutorado Acadêmicos). Realiza na UFMG trabalhos vinculados ao Programa Transdisciplinar de Extensão, Ensino e Pesquisa Social Aplicada Polos de Cidadania, da UFMG, no qual é membro da equipe de Coordenação Geral e Acadêmica; no âmbito deste programa se insere o Projeto Socioambiental de Ações de Organização e Mobilização Social, Proteção e Efetivação de Direitos Fundamentais na Comarca de Conceição do Mato Dentro, entre os anos de 20I4 a 20I8, em que se desenvolveu a pesquisa que resultou no livro ora resenhado.

Já o autor Lucas Furiati de Oliveira é Mestre em Psicologia Social pela UFMG, atuou como coordenador técnico do Programa de Extensão Polos de Cidadania, vinculado à Faculdade de Direito da UFMG por seis anos; foi também coordenador do Projeto Socioambiental de Ações de Organização e Mobilização Social, Proteção e Efetivação de Direitos Fundamentais na Comarca de Conceição do Mato Dentro entre os anos de 2014 a 2018 , e os trabalhos realizados neste projeto resultaram na obra ora analisada.

O livro Violências de mercado e de Estado no contexto do Empreendimento Minerário Minas-Rio, Conceição do Mato Dentro-MG, 2015 a 2017 fundamentou-se no estudo de caso em que se analisou diversos conflitos, como os socioambientais e os coletivos das comunidades existentes no entorno do empreendimento de mineração Minas-Rio, mas restringiu o escopo dos trabalhos às violações aos direitos humanos; além disso, a criação da obra resenhada decorreu da ação que envolveu a análise do parecer técnico que representa um dos resultados dos estudos e da avaliação da situação encontrada durante a pesquisa realizada no âmbito do Programa Polos de Cidadania da Faculdade de Direito da UFMG e do Projeto Socioambiental de Ações de Organização e 
Mobilização Social, Proteção e Efetivação de Direitos Fundamentais na Comarca de Conceição do Mato Dentro, entre os anos de 2014 a 2018.

Os objetivos do estudo, dentre outros, foram no sentido de identificar os danos e os impactos sociais, ambientais, econômicos e políticos sofridos pelos moradores prejudicados que vivem em comunidades da cidade de Conceição de Mato Dentro, no estado de Minas Gerais, bem como demonstrar que essas lesões a direitos humanos tiveram como causa a construção e a operação da mina e do mineroduto do empreendimento Minas-Rio.

O livro estruturou-se em três capítulos: no primeiro, destaca-se o trecho em que discorre sobre a metodologia acolhida no trabalho, bem como apresenta o formato e a natureza dos dados e os documentos levantados durante atividades de pesquisa e extensão. Assim adotou-se a técnica metodológica de pesquisa-ação, além de coletar informações e documentações nas ações de extensão que serviram para direcionar e desenvolver a pesquisa, objetivando a produção de conhecimento científico.

No segundo capítulo, analisou-se os abusos aos direitos humanos das pessoas que foram afetadas pelo empreendimento Minas-Rio. Para tanto foram examinados os documentos dos processos de licenciamento de instalação e operação, apresentando diversas comprovações que foram obtidas, principalmente, pelo trabalho de campo realizado no âmbito do citado programa de extensão. Esse estudo constatou a necessidade de atuação transdisciplinar para evitar as percepções fragmentadas e desconexas relacionadas à transgressão a direitos. Além disso, analisou-se os documentos técnicos, mas sem excluir a participação da população afetada negativamente pela atividade de mineração, verificação instrumentalizada, predominantemente, por meio de depoimentos e denúncias das pessoas envolvidas e prejudicadas.

Ainda no segundo capítulo, constatou-se e enumerou-se os direito humanos violados, ressalvando que pode ter havido mais direitos transgredidos além daqueles identificados; observou-se também que o direito ao contraditório nos processos administrativos de licenciamento do empreendimento Rio-Minas não foi desenvolvido de forma a tentar ouvir e atender as reinvindicações das famílias e das pessoas que vivem nas proximidades da mineradora, que passaram a conviver, por exemplo, com a poluição de cursos d'água por falha na execução das fases de implantação da mineradora. Outras falhas foram relatadas, inclusive nos documentos técnicos em que a falta de 
atendimento a condicionantes estabelecidas nas fases iniciais do licenciamento não impediu a aprovação dos licenciamentos posteriores para implementar a execução da operação da empresa mineradora em Minas Gerais.

No terceiro capítulo, concluiu-se o trabalho apresentando as considerações finais e as recomendações. Uma das considerações relatadas foi a atuação seletiva do Estado, que implementa e autoriza ações baseadas no interesse econômico em detrimento dos cidadãos atingidos em decorrência do empreendimento minerário Minas-Rio. Ademais, recomendações foram apresentadas, sendo a mais relevante a necessidade de se estabelecer oficialmente o conceito e a definição de "atingido", inclusive a abrangência desse termo, pois somente assim haverá a oportunidade de negociações para garantir e efetivar os direitos das pessoas que vivem nas comunidades de Conceição do Mato Dentro e região que foram atingidas negativamente pelo empreendimento de mineração Minas-Rio. Salientou-se ainda que a definição do referido conceito deverá englobar os mais diversos danos e não pode ser delimitada apenas pela área correspondente à jazida mineral.

O livro ora resenhado é resultado das atividades de ensino, pesquisa e extensão do Programa Transdiciplinar Polos de Cidadania da Faculdade de Direito da UFMG, criado em I995 e implementado pela Faculdade de Direito da UFMG. Esse programa objetiva a efetivação dos direitos humanos e a construção de conhecimento baseado no diálogo entre diversos saberes. O método da pesquisa-ação tem sido aplicado nas atividades de ensino, pesquisa e extensão do Programa, além disso “a característica marcante, presente em todas as metodologias empregadas pelo Programa, é o envolvimento ativo da própria comunidade em uma atuação interativa e emancipadora, com o objetivo de redução dos índices de desigualdades e riscos sociais, assim como o fortalecimento da cidadania e das autonomias dos sujeitos" (POLOS DE CIDADANIA, 2020).

A obra analisada demonstra-se relevante, principalmente, por adotar e aplicar a pesquisa-ação nos trabalhos de pesquisa, pois esse método objetiva interferir por meio de ações relacionadas ao objeto pesquisado a fim de solucionar um ou mais problemas identificados pelo pesquisador; dessa forma, proporciona a transformação da realidade de forma prática e não apenas teoricamente. 
O método da pesquisa-ação utiliza uma abordagem colaborativa entre pesquisador e participantes que visa tanto a resolução de problemas como a produção de novos conhecimentos, ou seja, “a questão central é promover mudanças oriundas da participação das pessoas em conjunto como o pesquisador, trazendo resultados práticos (para as pessoas, comunidades e organizações) e teóricos (pra a comunidade científica)" (GIBERTONI, 20I2, p. 30).

"Não se trata de simples levantamento de dados ou de relatórios a serem arquivados. Com a pesquisa-ação os pesquisadores pretendem desempenhar um papel ativo na própria realidade dos fatos observados" (THIOLLENT, 20II, p. 22 ), sendo assim, percebe-se na obra resenhada a atuação ativa e colaborativa dos pesquisadores em relação ao objeto pesquisado - por exemplo, quando são apresentados no livro registros captados pela equipe de pesquisa, como fotos de despejos de moradores, ocorridos durante a investigação acadêmica, entre outros acontecimentos.

A pesquisa-ação possui ainda pressupostos específicos como: “a) a existência de um problema coletivo (de uma instituição, associação, empresa, comunidade, etc.); b) o envolvimento solidário e dialógico de todos os participantes; c) a participação na investigação, como sujeitos e não só como informantes” (GUSTIN; DIAS, 20I3, p. 90), sendo assim, é possível perceber que a pesquisa nesses moldes adequa-se aos conflitos socioambientais identificados nas comunidades que sofrem com a instalação e o funcionamento do empreendimento de mineração Minas-Rio. Além disso, essa técnica pode influenciar e modificar o objeto investigado, pois, como anteriormente apresentado, "a pesquisa-ação favorece a resolução de problemas coletivos, a transformações de realidades emergentes e a produção de conhecimento" (GUSTIN; DIAS, 2013, p. 89).

A integração do programa Polos de Cidadania com ensino, pesquisa e extensão universitária efetivou investigações multidisciplinares no ambiente das ciências sociais aplicadas, subsidiando ainda a publicação do livro analisado, que tem como técnica metodológica a pesquisa-ação, um “método de referência empírica, que estabelece o inter-relacionamento permanente entre as atividades de pesquisa e de ação e que mantém um claro compromisso com a transformação social e com a produção de conhecimento" (GUSTIN; DIAS, 20I3, p. 88). Nesse sentido, o livro desempenha o papel de apresentar o resultado da pesquisa-ação no contexto do empreendimento minerário 
Minas-Rio e também como a pesquisa promoveu a produção do conhecimento acadêmico, transformando a realidade das comunidades envolvidas devido à implementação de serviços de assessoria técnica e mediação de conflito, por exemplo.

Portanto, observa-se que para efetivar direitos, além produzir conhecimento, a pesquisa-ação mostra-se necessária para alcançar tais objetivos; ademais, a obra examinada integra principalmente a produção acadêmica da esfera jurídica, mas destaca-se por adotar a técnica metodológica pesquisa-ação para produzir conhecimento científico, além de responder as questões jurídicas com base em diferentes áreas do conhecimento, como direito, economia e ciências socioambientais, e de permitir atuações científicas que sejam efetivamente propulsoras de mudanças na realidade social, que, por vezes, apresenta situações socialmente e juridicamente fragilizadas pelo contexto da mineração estudada e apresentada no livro em análise e pelos desastres ambientais recentemente ocorridos no Brasil.

\section{Referências}

GIBERTONI, Daniela. A contribuição da pesquisa-ação na construção do conhecimento científico na Engenharia de Produção brasileira. 20ı2. I93 f. Tese (Doutorado em Engenharia de Produção) - Universidade Federal de São Carlos, São Carlos, SP, 20 I2.

GUSTIN, Miracy Barbosa de Sousa; DIAS, Maria Tereza Fonseca Dias. (Re)pensando a pesquisa jurídica. 4. edição. Belo Horizonte: Del Rey, 2013.

POLOS DE CIDADANIA. Arquitetura do Programa Transdisciplinar Polos de Cidadania, extensão, ensino e pesquisa social aplicada. Polos de Cidadania, 2020. Disponível em: https://polos.direito.ufmg.br/. Acesso em: ig set. 2020.

THIOLLENT, Michel. Metodologia da pesquisa-ação. I8. edição. São Paulo: Cortez, 20 II. 


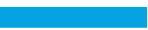

